\title{
Improving teaching in different disciplines of natural science and mathematics with innovative technologies
}

\author{
Umitzhan Kossybayeva ${ }^{1}$ (D) - Bagit Shaldykova ${ }^{2}$ Danna Akhmanova ${ }^{1} \cdot$ \\ Svetlana Kulanina ${ }^{3}$
}

Received: 16 November 2021 / Accepted: 10 February 2022 / Published online: 25 February 2022

(c) The Author(s), under exclusive licence to Springer Science+Business Media, LLC, part of Springer Nature 2022

\begin{abstract}
The study describes an innovative methodology for teaching natural and mathematical sciences in the context of distance learning using modern technological solutions and based on the concepts of active social learning that involves constructivist, problem-oriented, project and research approaches. The proposed methodology was tested on 80 students enrolled in two training courses in [BLINDED] University and [BLINDED] University, respectively: Mathematics Teaching in the Content and Language Integrated Learning (CLIL) context and Molecular Biology. The psychological safety of the proposed pedagogical methodology was investigated by assessing the level of psychological well-being of the participants in the educational process using the Scale of psychological well-being questionnaire developed by $\mathrm{C}$. D. Ryff that was adapted to the educational context. The results of the study showed that the proposed pedagogical methodology was safe in relation to the life of students. It generally improved their perception of learning and themselves in the role of its participants, promoted positive self-esteem in group learning contacts, and, by developing learning involvement and interest through the Clil technology, qualitatively contributed to the achievement of educational progress by each student. The developed innovative methodology for teaching natural and mathematical sciences can be used as a pedagogical model for developing effective training courses. The demonstrated assessment of the level of psychological well-being adapted to the educational context can serve as a basis for the development of motivational learning strategies that support students in crisis learning conditions during the pandemic.
\end{abstract}

Keywords Clil technology · Distance learning · Innovative teaching methods · Motivational learning strategy $\cdot$ Natural and mathematical sciences $\cdot$ Psychological well-being

Umitzhan Kossybayeva

kossybayevaum@rambler.ru; umit1980@mail.ru

Extended author information available on the last page of the article 


\section{Introduction}

The rapid development of information technology has led to the reassessment of the importance of many types of activities and a significant change in their nature (Melnikov et al., 2020). In the twenty-first century, the use of technology as a learning tool is becoming a crucial component of learning. In education, technology has introduced a new tool that can reinforce the skills of learners across all fields of study and age groups. Increasingly, the power of technology enables learning and interaction even in the most remote areas of the developing world. This digital revolution is fueled by the penetration of broadband and the ubiquity of smartphones, especially among teachers and students of the new era who are easily absorbing the trendy culture of leisure and learning. The introduction of innovative cloud technologies into educational processes gives students endless opportunities to participate in cutting-edge research and educational initiatives. Open educational resources in various formats such as videos, pdf and MP3 files are becoming the backbone of modern learning strategies (Iji \& Abah, 2018).

There are great changes in teaching natural and mathematical sciences driven by technology and digital learning (Klingenberg et al., 2020). Due to the fact that natural and mathematical sciences should be integrated into the learning process as they are aimed at forming holistic ideas about the physical world, as well as the connections between objects based on leading ideas and concepts (Luneeva \& Zakirova, 2017), most universities around the world include mathematics in many programs they teach. This reflects the vital role that mathematics must play in creating an innovative and productive workforce. Today, there are many open-source e-learning tools that make it possible to integrate technology into mathematics teaching (Akugizibwe \& Ahn, 2020; Czerkawski \& Berti, 2021). These models can help create learner-centered experiences that are interactive and supportive of the acquisition of scientific knowledge. The use of digital tools promote skills and strategies that are essential in the natural sciences, such as solving real-life problems or visualizing complex patterns. Adaptive digital tools allow students to receive content in accordance with their individual learning styles and implement the knowledge they gained earlier (Hillmayr et al., 2020). A specialist should possess a range of competencies. These include the ability for self-education, technology proficiency, independent decision-making, adaptability in the changing social and professional environment, teamwork, and stress tolerance. CLIL approach seeks to instill the exact same competencies (O’Dowd, 2018).

The COVID-19 pandemic has triggered considerable changes in higher education associated with the rapid transition to online learning and the re-configuration of physical and virtual learning environments (Bakker et al., 2021). The widespread adoption of stream-based learning is at the heart of the educational paradigm shift. Thus, teachers use remote communication tools to communicate and interact with students, as well as to deliver lectures and conduct classes through software interfaces in real-time. Meanwhile, students rely on online collaboration platforms and active group learning with peers. Given the importance of stream-based learning in the ongoing period of the COVID-19 pandemic, as well as its expected relevance 
in the coming hybrid educational era, it is important to explore opportunities to improve the educational experience and seek innovative solutions to sustainably support quality digital pedagogy (Chen et al., 2021). In the context of distance learning, theoretical material is effectively delivered to students through audio or video broadcasting, text materials, or presentations. There is a serious problem related to the conduct of hands-on and laboratory classes in the field of non-humanitarian disciplines, where the formation of competencies occurs in the process of using laboratory equipment and interacting with technical means (Soroko, 2021). In addition, the COVID-19 pandemic has increased the need for interactive and engaging learning environments as the forced transition to distance learning has resulted in learning generally limited to discussions and lectures delivered through video conferencing tools such as Zoom (Childs et al., 2021).

In this regard, the purpose of the study is to develop an innovative methodology for teaching natural and mathematical sciences in the context of distance learning using modern technological solutions that support educational practices. The following research tasks have been set:

- to develop an innovative teaching methodology based on the concepts of active social learning using the modern approaches of STEM education, Content and Language Integrated Learning (CLIL), namely constructivist, problem-oriented, project and research approaches, and implement it into an online training course;

- to test the proposed teaching approach on students taking the Mathematics Teaching courses and Molecular Biology in the [BLINDED] University and [BLINDED] University;

- to assess the level of psychological well-being of the participants in the educational process using the Scale of psychological well-being questionnaire developed by C. D. Ryff and adapted to the educational context in order to determine the psychological safety of the proposed pedagogical methodology;

- to compare self-reported estimates of student progress between the selected disciplines.

\section{Methods and materials}

\subsection{Research design}

In the context of the restrictions caused by the pandemic, the educational process in higher educational institutions of Kazakhstan and the Russian Federation in 2020-2021 was implemented online. In this regard, there was a need to develop innovative teaching methods for their further implementation in online training courses. The authors developed an innovative methodology for teaching disciplines of natural science and mathematics. It builds on the concepts of active social learning and integrates modern approaches from STEM education and Content and Language Integrated Learning (CLIL). These include the constructivist, problem-oriented, project-based and research approaches. The proposed methodology has been 
adapted to the implementation of educational activities in an online learning environment (Fig. 1).

In pedagogical practice, the implementation of pedagogical teaching methods is carried out using the innovative capabilities of digital technologies, such as LMC learning management systems, online communication services, specialized mobile applications, as well as immersive AR / VR / XR technologies. The educational content that fills the educational course is developed with the aim of updating knowledge and its application in practice and directs the student to the stable development of professional competencies and teamwork skills in the process of active

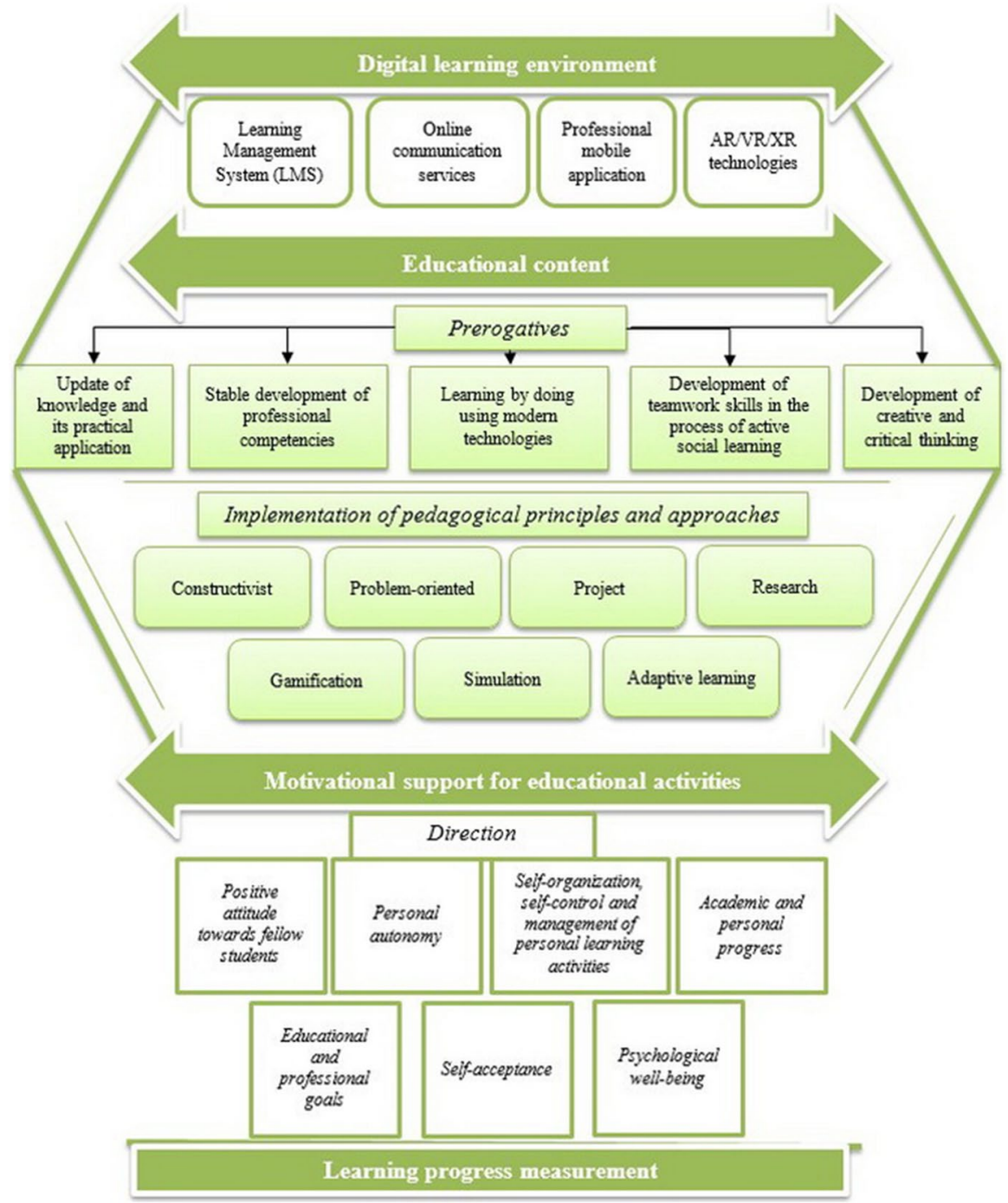

Fig. 1 Pedagogical Methods of Teaching Natural and Mathematical Sciences. * own development 
social learning, the development of creative, critical thinking and digital literacy. The introduction of a pedagogical model for teaching natural and mathematical sciences involves the implementation of such pedagogical principles as: adaptive learning, modeling and imitation, gamification, as well as constructivist, problemoriented, project, research approaches. Motivational support for educational activities in the process of implementing pedagogical methods in practice is an effective tool for achieving educational goals, by creating conditions for personal autonomy, educational and personal progress, self-organization, self-control and management of personal learning activities, supporting a positive attitude towards colleagues in training, psychological well-being and self-acceptance.

The innovative methodology was tested from January 2020 to June 2021 as part of the study of Molecular Biology and Mathematical Analysis. The educational experiment involved 80 students: 40 students in the [BLINDED] University and 40 students in the [BLINDED] University (Table 1).

The innovative pedagogical model was tested within the framework of two educational courses Molecular Biology and Mathematical Analysis, which, according to the moderators, made it possible to more contrastly determine its adaptability to different educational content of the natural and mathematical sciences.

The Mathematics Teaching course, combined with the CLIL technology, aims to deliver the fundamental knowledge by offering students some crucial practical and theoretical problems to solve. These problems refer to various areas of mathematics that are taught at school. The primary objectives of the course are to help students develop logical thinking and teach them the basic methods of analysis and modeling. In CLIL methodology, language appears as a tool for learning other subjects and developing the abilities to rethink the learning process, engage others, and instill communicative competencies. CLIL seeks to make teacher students proficient with innovative teaching methods in the classroom. The technology involves the independent learning of content (video lectures, tests and electronic documents) in an e-learning environment and practical assignments. The course was delivered in English.

The Mathematics Teaching course was tested on 40 students in the [BLINDED] University. It was developed using Matematica, WolframAlpha, Photomath, BuzzMath, and ACT Math: Data Analysis.

The Molecular Biology course is one of the basic training courses as it introduces the main concepts that modern biology is based on. Students acquire knowledge about biopolymer structure, units, and functions, as well as the basic principles of coding, storage and implementation of genetic information, the

Table 1 Participants in the educational experiment

\begin{tabular}{llll}
\hline $\begin{array}{l}\text { Number of } \\
\text { students }\end{array}$ & Age & Gender & University \\
\hline 40 & $22-26$ & M-17, F-13 & [BLINDED] University \\
40 & $21-23$ & M-23, F-17 & [BLINDED] University \\
\hline
\end{tabular}

* own development 
structure and function of genes and genomes. This course reveals the content, theoretical and practical problems of molecular biology as a science about the structural features and properties of molecules that ensure the existence of a biological form of the motion of matter, as well as its place and role in the group of sciences that make up modern physicochemical biology. The experiment based on the Molecular Biology course was attended by 40 students of [BLINDED] University. Individual practical tasks for students studying Molecular Biology were developed with the help of mobile applications such as Genetics and Molecular Biology; Molecular Methods; WebMO Molecule Editor; Molecular Biology Quiz / MCQsLearn; Molecular Biology MCQ.

The three disciplines were taught based on similar procedures in order to determine such characteristics of an innovative pedagogical model as universality and adaptability to different educational programs. The courses were divided into 10 thematic modules. Within the framework of each course, lectures were delivered with the help of the online meeting software Microsoft Teams (Microsoft, 2021). The curators of the courses gave 10 online lectures with the provision of access to a multimedia educational resource. To ensure the acquisition of knowledge and the development of students' awareness of its practical application, a channel was created on the Telegram social network. Thus, the curators of the courses posted information on modern achievements in the field of molecular biology and mathematical analysis.

The tasks were developed and distributed within team projects with the help of the Teamer management system (Teamer, 2021), which ensured the coverage of a number of assignments on one platform, the connection of each task with instructions, as well as group project activities clearly scheduled and timed. The service allowed the teachers to track the progress of each student in real-time. Teamer includes three sections: 'What to do?' (educational tasks), 'Who is to blame?' (todo calendar) and 'Where is everyone?' (database of the project group participants). Using the platform, the course curators planned the schedule and the order of assignments, as well as implemented group project-based activities.

To ensure communication between the participants in the educational experiment and motivation for educational activities, a group was created on Facebook. The course curator developed digital motivational learning content, which included video, audio, images, and quizzes conceptually based on the theory of positive psychology and psychological well-being. The social interaction of students in the learning process was observed by a representative of the Center for Coordination of Educational Projects of [BLINDED] University.

The structure of educational activities is presented in Fig. 2.

In order to determine the psychological safety of the proposed model, the level of psychological well-being of the participants in the educational process was assessed using the Scale of psychological well-being questionnaire developed by Ryff (1995) and adapted to the educational context by the course curators. This questionnaire consisted of 84 items and included 6 scales and an integral indicator of psychological well-being of the participants in the educational process.

The study participants were surveyed twice-at the end of the first month of training and at the beginning of the last one-in order to study changes in the 


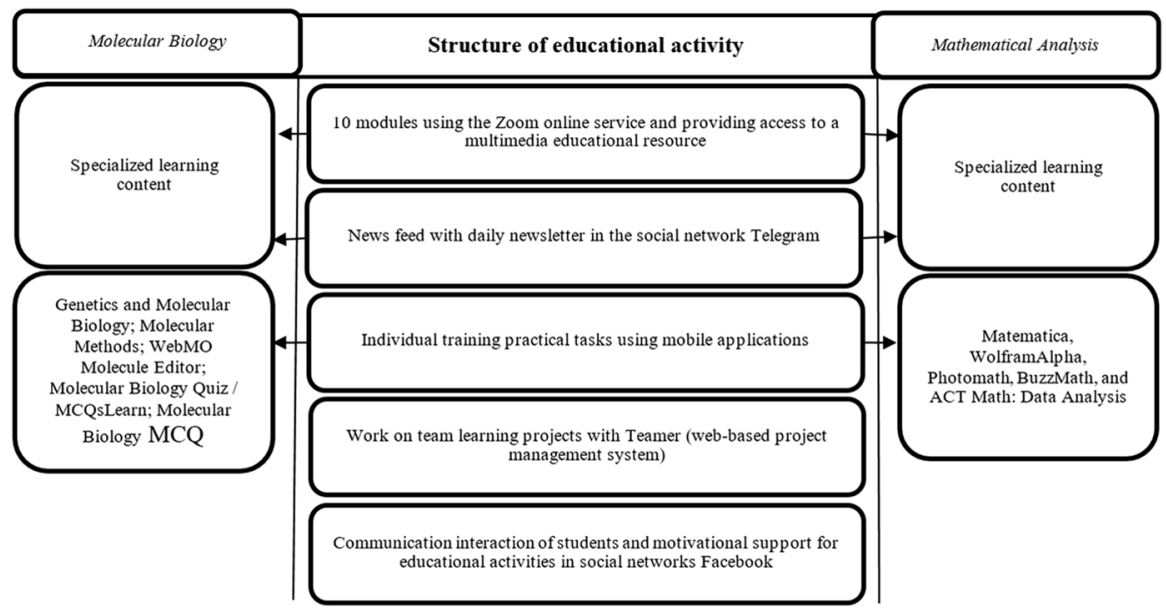

Fig. 2 The structure of educational activities. * own development

indicators of psychological well-being under the influence of the proposed teaching methodology.

The students were given a list of statements related to their feelings about themselves and their learning. They were asked to circle the number that best reflected the degree of their agreement/disagreement with each statement (Table 2).

The statements are assigned points equal to the numerical value of the answer in the answer sheet. Some of the items are interpreted as reverse values (Table 3).

\subsection{Ethical issues}

Before the survey, the participants familiarized themselves with the goals and objectives of the study and provided written consent to participate in the educational experiment. All participants were informed that there would be no reward or punishment for their participation or refusal.

\subsection{Data analysis}

The Survio service (Survio, 2021) was used to create the questionnaire and process the data obtained. Survio is an efficient solution for making questionnaires, collecting and analyzing data, and sharing the results obtained. The results were assessed both with reference to each participant in order to determine the attitude and educational intentions of the student and in the context of the group while involving the calculation of average values, which were used to study the influence of the pedagogical methodology being tested on the change in the indicators under consideration.

Due to the small size and structure of the sample, the data obtained are preliminary and superficial and have not been generalized. Further quantitative studies with 


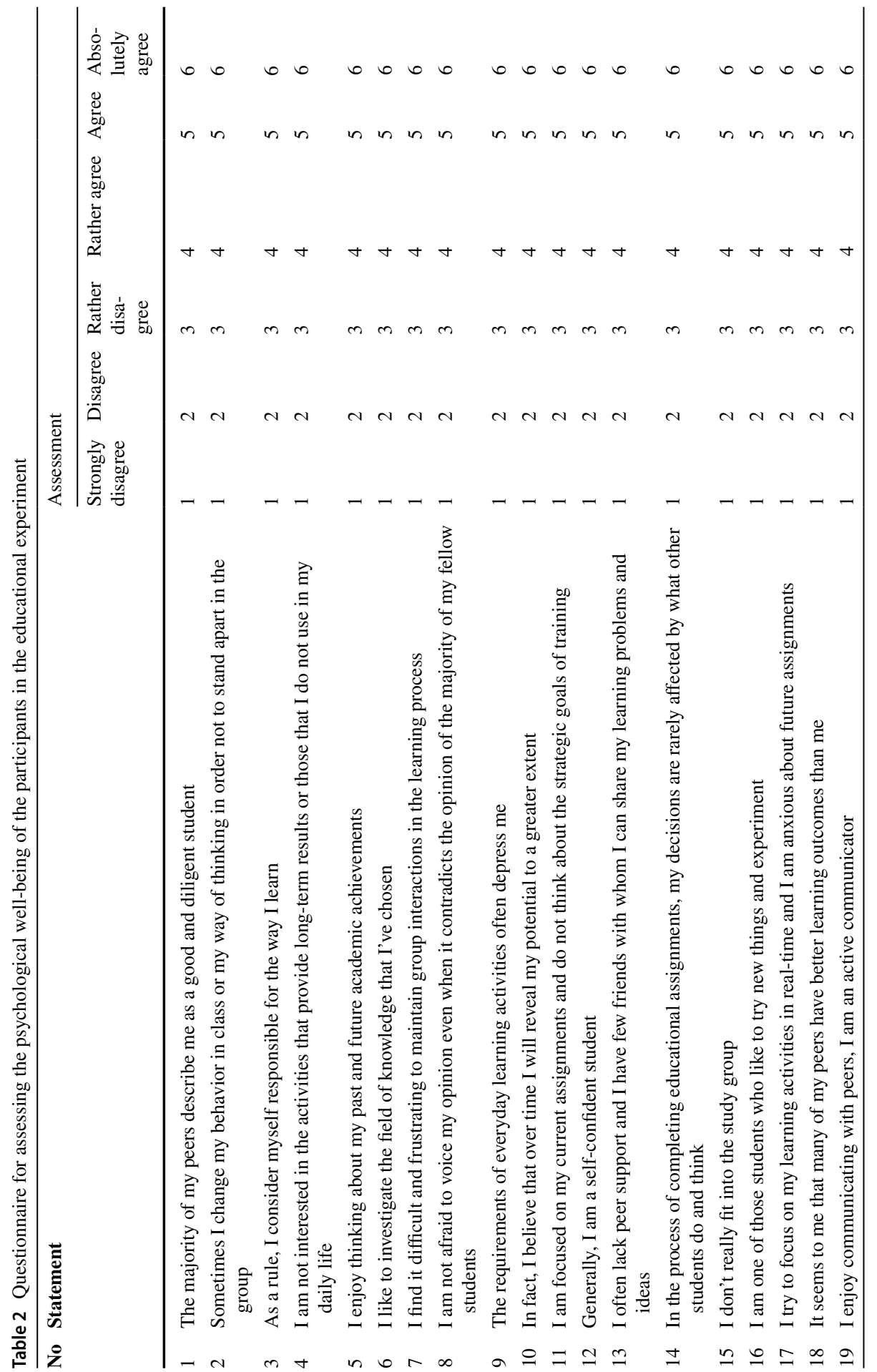




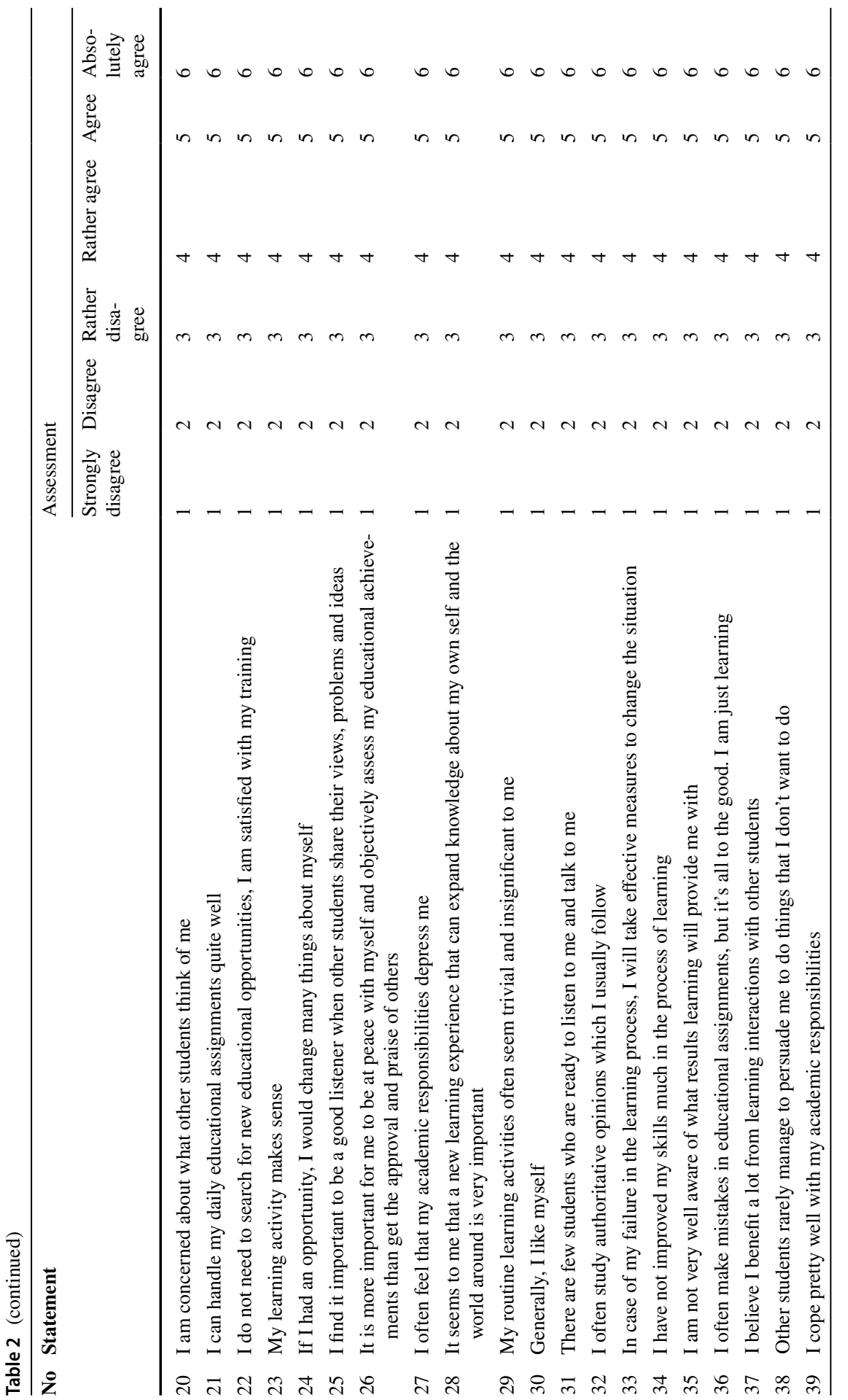




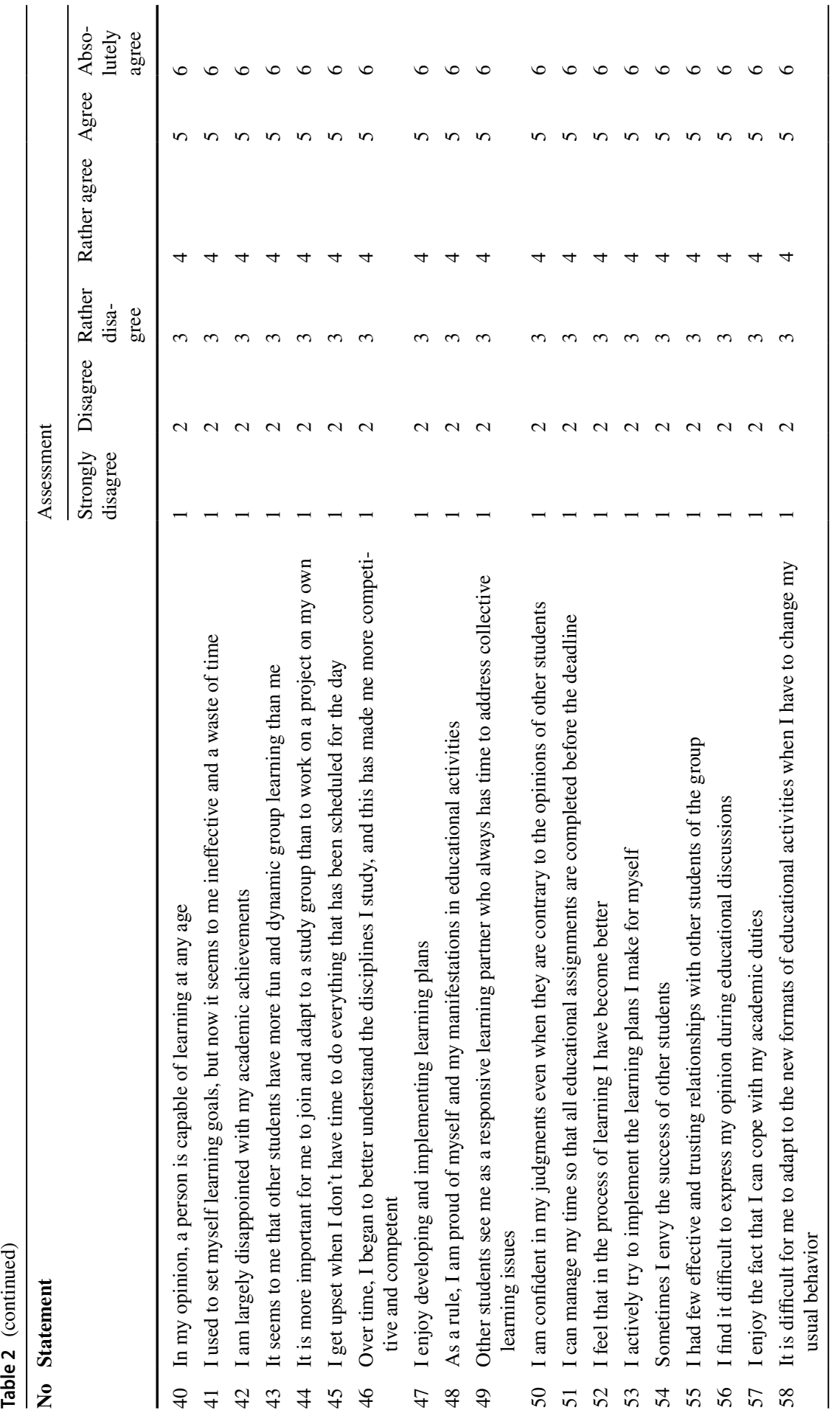




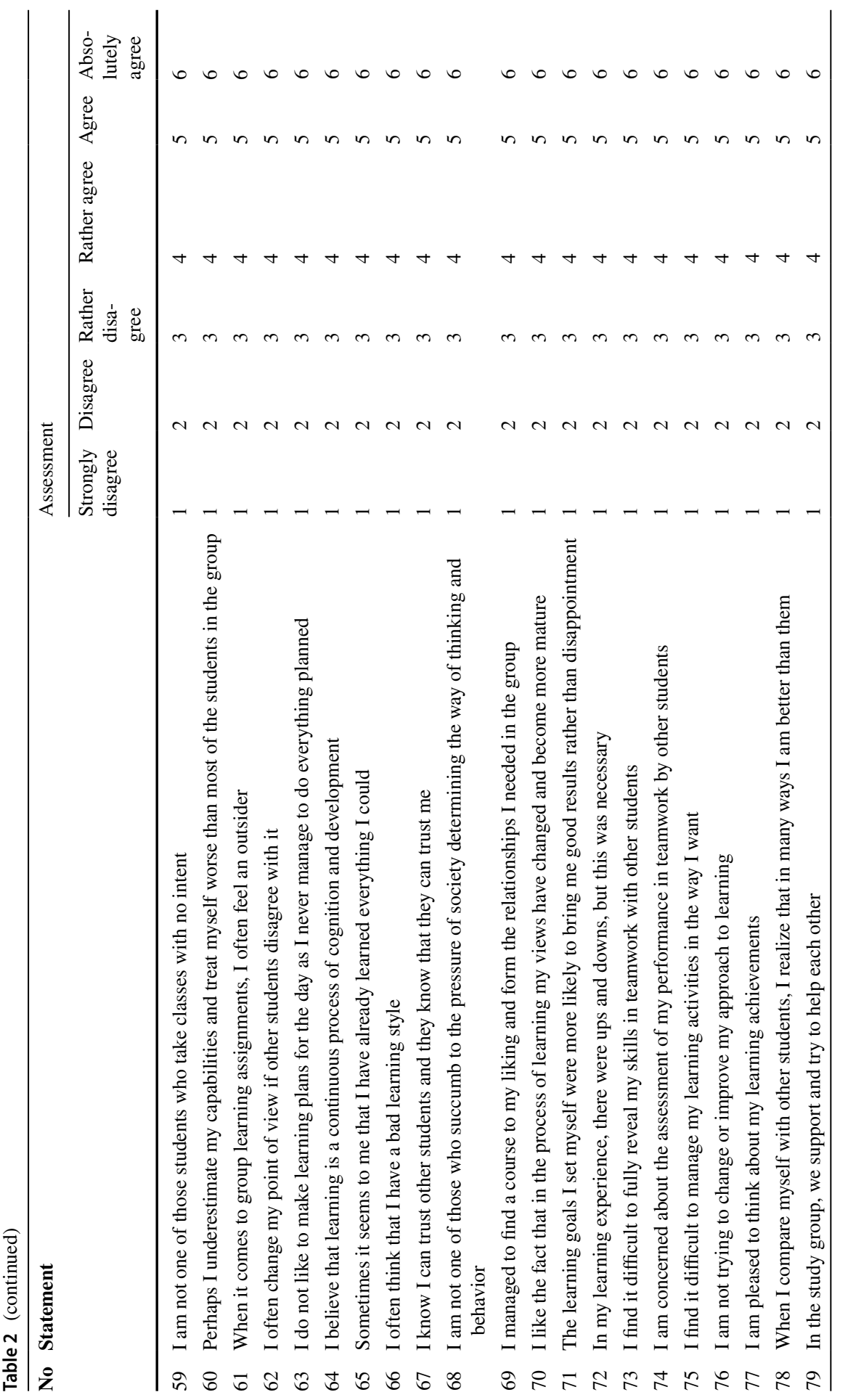




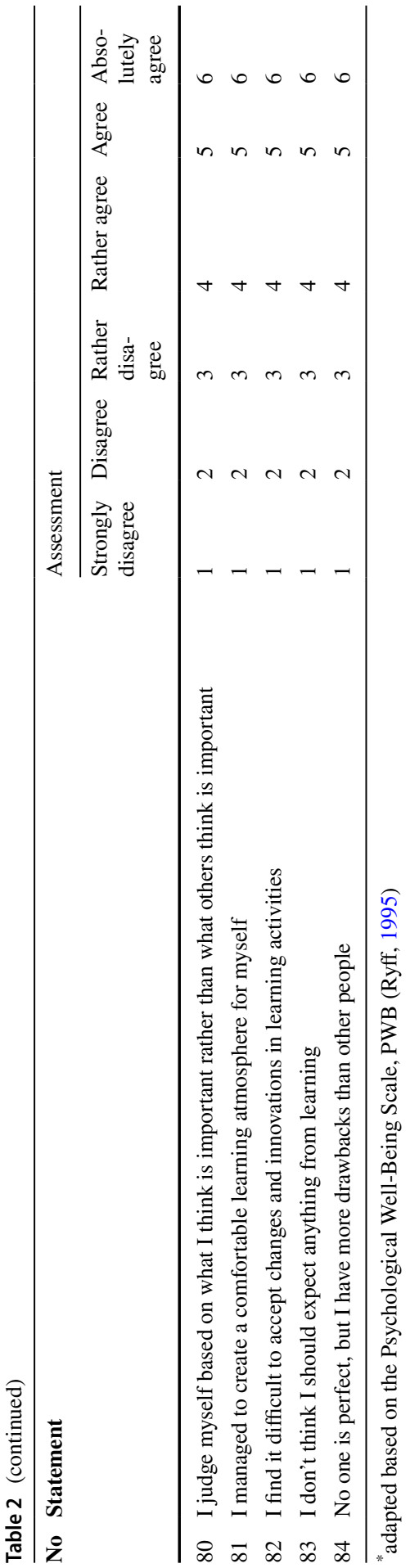




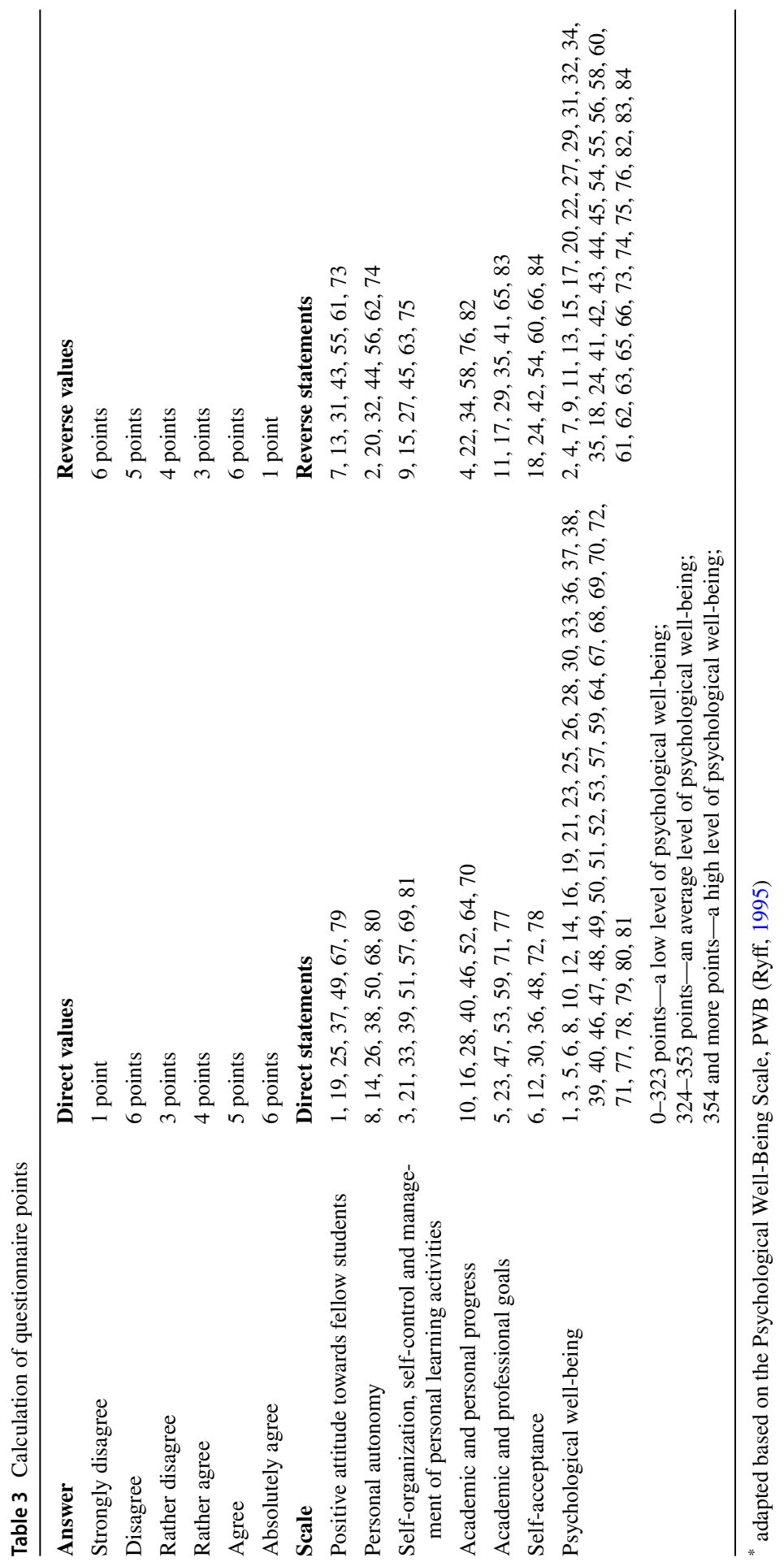


a larger and more balanced sample are needed to identify the impact of the proposed methodology on the effectiveness of educational activities.

\section{Results}

The proposed pedagogical model focuses on the applied nature of learning in the context of the possibilities of the digital space and motivational support for the participants in the educational process. The prerogatives of practical educational activities are the update of knowledge and its application in practice; stable development of professional competencies; learning by doing using modern technologies; development of teamwork skills in the process of active social learning; development of creative and critical thinking.

In the course of studying Molecular Biology, the students had an opportunity to familiarize themselves with scientific information about various molecular methods that are currently used in molecular laboratories, perform interactive tasks and assess their knowledge by participating in exciting quizzes. The functionality of the mobile applications given in the course promoted applied and fun learning. The Genetics and Molecular Biology app (AJAX MEDIA TECH PRIVATE LIMITED) made it easy and fun for the students to learn molecular biology by visualizing colorful images and videos. The WebMO Molecule Editor (WebMO, LLC) application allowed students to create and view molecules in three-dimensional space, visualize orbitals and symmetry elements, search for chemical information and properties in external databases, and access modern computational chemistry programs. The Molecular Biology Quiz / MCQsLearn (Molecular Biology Trivia Quiz) application provided learners with an opportunity to test their knowledge in the field of molecular biology based on more than 600 + questions related to bioinformatics; biological membranes, biotechnology and recombinant DNA; replication, recombination and DNA repair; free radicals and antioxidants; genetics, immunology; the human genome project; insulin and glucose homeostasis; xenobiotic metabolism; prostaglandins and related compounds; the regulation of gene expression; biochemistry tools. To assess knowledge, the Molecular Biology MCQ (RajalakshmiRTY) application containing more than 10,000 questions was used.

Students enrolled in the Mathematics Teaching course could learn the basic concepts and methods used in the Theory of Limits and innovative methods of teaching mathematics at school using the CLIL technique. The software solutions considered within the course were Mathway, Microsoft Maths Solver, Brainly, Mathematical Analysis, WolframAlpha, Photomath, BuzzMath, and ACT Math: Data Analysis. When performing the practical tasks, students determined the possibilities of applying theorems and methods of mathematical analysis to formulate and solve applied problems. They also calculated the limits of functions, performed differentiation and integration, calculated integrals, for expanded functions into series in English.

In the proposed pedagogical methodology, motivational support is carried out in the field of the formation and promotion of a positive attitude towards fellow students; the development of personal autonomy; the improvement of the skills of self-organization, self-control and management of personal learning activities; the 
Table 4 The results of the survey at the beginning and end of the course Molecular Biology

\begin{tabular}{lllll}
\hline Indicator & Average (points) & $\begin{array}{l}\text { Start of } \\
\text { educational } \\
\text { practice }\end{array}$ & $\begin{array}{l}\text { End of educa- } \\
\text { tional practice }\end{array}$ & $\begin{array}{l}\text { Deviation of } \\
\text { indicators } \\
(-/+)\end{array}$ \\
\hline $\begin{array}{l}\text { Positive attitude towards fellow } \\
\text { students }\end{array}$ & 63 & 49 & 58 & +9 \\
$\begin{array}{l}\text { Personal autonomy } \\
\text { Self-organization, self-control and }\end{array}$ & 56 & 50 & 58 & +8 \\
$\quad$ management of personal learning & & 47 & 56 & +9 \\
$\quad$ activities & 65 & & & +12 \\
$\begin{array}{l}\text { Academic and personal progress } \\
\text { Academic and professional goals }\end{array}$ & 63 & 56 & 68 & +13 \\
$\begin{array}{l}\text { Self-acceptance } \\
\text { Psychological well-being }\end{array}$ & 59 & 54 & 67 & +13 \\
\hline
\end{tabular}

* own development

Table 5 The results of the survey at the beginning and end of the course The Mathematics Teaching

\begin{tabular}{lllll}
\hline Indicator & Average (points) & $\begin{array}{l}\text { Start of } \\
\text { educational } \\
\text { practice }\end{array}$ & $\begin{array}{l}\text { End of educa- } \\
\text { tional practice }\end{array}$ & $\begin{array}{l}\text { Deviation of } \\
\text { indicators } \\
(-/+)\end{array}$ \\
\hline $\begin{array}{l}\text { Positive attitude towards fellow } \\
\text { students }\end{array}$ & 63 & 41 & 45 & +4 \\
$\quad$ Personal autonomy & 56 & 55 & 67 & +12 \\
$\begin{array}{l}\text { Self-organization, self-control and } \\
\text { management of personal learning }\end{array}$ & 57 & 45 & 57 & +12 \\
$\quad$ activities & 65 & & & \\
$\begin{array}{l}\text { Academic and personal progress } \\
\text { Academic and professional goals }\end{array}$ & 63 & 53 & 62 & +9 \\
$\begin{array}{l}\text { Self-acceptance } \\
\text { Psychological well-being }\end{array}$ & 59 & 59 & 66 & +7 \\
\hline
\end{tabular}

* own development

achievement of educational and personal progress; the development of technology literacy in setting educational and professional goals; support for psychological well-being and self-acceptance.

In order to ensure a personalized approach to learning and measure the degree of safety of the tested teaching methodology, at the beginning and at the end of training, the level of psychological well-being of the participants in the educational process was investigated. The results from the assessment of the psychological wellbeing of students engaged in Molecular Biology (Tables 4 and 5) and Mathematics Teaching are described based on the analysis of the priority of beliefs.

The Cronbach Alpha test was used to determine the reliability and internal consistency of the assessment method used, as well as the reliability of students' selfassessment. The study of the results of the survey of Cronbach Alpha methods 
showed a high internal consistency of the characteristics describing the studied object $(\alpha=0.751)$. This result allows the descriptive statistics to be judged to be more representative.

Based on the results of the survey, it can be concluded that the educational practice offered by the course had a positive impact on the level of psychological wellbeing of the participants.

The level of positive attitude towards each other among the participants in the Molecular Biology course increased by nine points and by 4 points among the participants in the Mathematics Teaching course. This indicates that the applied pedagogical methodology contributed to the formation of effective and trusting interpersonal relationships in the group and promoted a proactive corporate culture allowing each participant to demonstrate their communication abilities, as well as to develop the skills of mutual assistance and support in group work.

The indicator of personal autonomy increased by eight points among the participants in the Molecular Biology course and by 12 points among the participants in the Mathematics Teaching course, which indicates that the teaching methodology contributed to the development of students' skills of independent learning, selforganization, responsible decision-making and the ability to critically assess their educational achievements in accordance with personal criteria.

In the process of learning, students studying Molecular Biology and Mathematics Teaching improved their skills of self-organization, self-control, and management of personal learning activities, on average, by 9 and 12 points, respectively. This testifies to the students' adaptation to digital pedagogy and acceptance of distance learning, mastery of the skills of learning activity management, and the effective use of the technological capabilities provided by the course.

The indicator of academic and personal progress, on average, increased by 12 points in the Molecular Biology group and by 9 points in the Mathematics Teaching group. This indicates that the pedagogical methodology tested in the training courses has demonstrated its effectiveness in the development of the professional and personal competencies of students and they started to consider themselves as self-actualizing individuals open to new knowledge and experience while revealing and realizing their potential to the fullest. The students showed a high level of mastery of the educational material, which was also evidenced by the results of the tests taken after each unit completion.

The students enrolled in the Molecular Biology course demonstrated an improvement in the skills of setting educational and professional goals, as evidenced by an increase in the indicator by 13 points. The students studying Mathematics Teaching improved their goal setting skills by 7 points.

The self-acceptance indicator, on average, increased by 13 points among the students studying Molecular Biology and by 9 points among the students enrolled in the Mathematics Teaching course, which indicates that educational activity influenced the positive self-esteem of the course participants by developing their ability to critically evaluate their own good and bad qualities and be congruent in group learning interactions.

The complex indicator of the psychological well-being of the participants in the educational experiment increased by 23 points among the students enrolled in the 
Molecular Biology course and by 18 points among the students studying Mathematics Teaching, which indicates that the proposed pedagogical methodology has demonstrated its safety in relation to the life processes of students, improved their perception of learning and themselves in the role of its participant, promoted positive self-esteem in group learning contacts, and by developing learning involvement and interest through the Clil approaches, qualitatively contributed to the achievement of educational progress by each student.

Figure 3 shows the personal progress of the students enrolled in the two courses mentioned above and trained in accordance with the innovative pedagogical methods of teaching natural and mathematical sciences based on the results of their self-analysis.

The results of testing the pedagogical model confirmed its versatility and adaptability to various types of educational content.

\section{Discussion}

Currently, students need both cognitive and practical learning experiences (Abramovich et al., 2019). In order to ensure an effective and efficient learning process, teachers should connect the educational content to everyday life and provide students with real examples and applications so that they can interact with the teacher, the educational material and the learning environment, as well as understand the importance of the discipline being studied (Algani, 2019). The learning environment in higher educational institutions, especially in the context of natural and mathematical sciences, requires deep learning supported by critical thinking and introspection (Santangelo et al., 2021), which fosters creativity and innovation (Khotimah et al., 2021). A rational and radical approach to the study of natural and mathematical disciplines draws attention to interdisciplinary interaction (Khirwadkar et al., 2020). In the learning process, students must think, solve problems, change their positions and opinions, develop skills and accumulate knowledge. The application of several

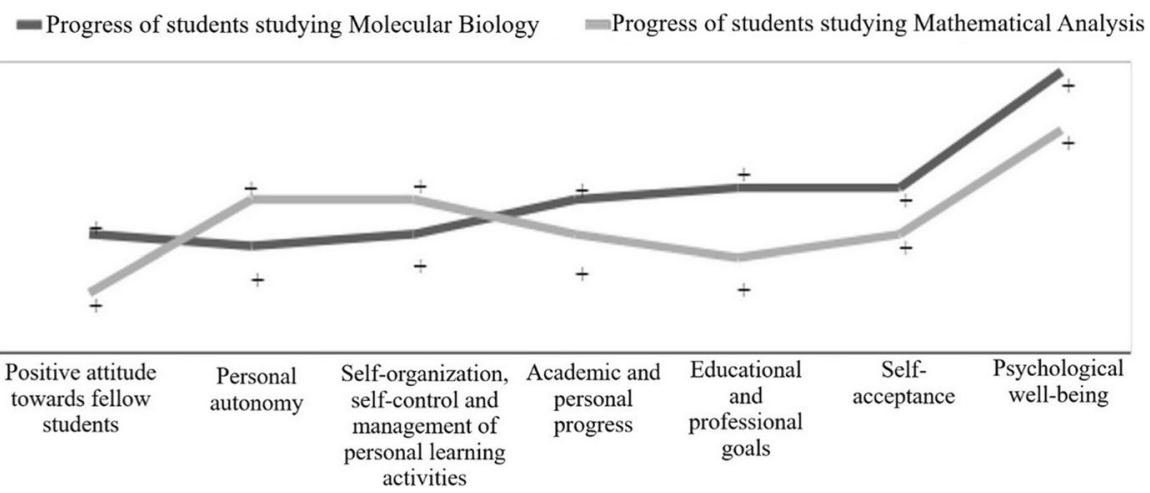

Fig. 3 Students' assessment of their own progress based on the learning outcomes of the courses. * own development 
pedagogical principles based on a constructivist paradigm can lead to good learning outcomes. The application of constructivist teaching methods is one of the cornerstones of science and technology and, in fact, represents the interaction between physical and cognitive activities (Algani, 2019). According to the constructivist theory, learning is an active process allowing students to construct knowledge (Allcoat et al., 2021). The STEM approach is closely related to the CBL approach, which encourages students to seek solutions to real-world problems using available digital tools (Leijon et al., 2021). Another approach that is prioritized in the STEM paradigm is project-based learning. The implementation of educational projects involves the creation of a subjectively new personally significant product focused on the formation of deep knowledge and meta-subject abilities, the development of independence, and increased interest in the studied subject (Luneeva \& Zakirova, 2017).

E-learning methods violate the stereotypes of teaching and learning processes by making it possible to teach and study regardless of location and time (Moreno-Guerrero et al., 2020). Technology integration enables educators to create learning experiences that actively and meaningfully engage students in the course content (Borba, 2021). Technology can significantly influence student attitudes and behavior, as well as increase their engagement and motivation (Novita \& Herman, 2021). Most of the online learning platform models are based on constructivist theories with an emphasis on fundamental design elements, collaboration elements, self-assessment, team assessment, and facilitator assessment. This type of learning environment is an integration of technology, content and people providing learning, social and technical support in achieving goals and learning objectives (Iji \& Abah, 2018). Due to the fact that social and interactive participation is an integral part of cognitive development, learning settings that are most conducive to interactive learning should be investigated (Wannapiroon et al., 2021). In addition, it becomes apparent that there is a need for greater exchange and interdisciplinary collaboration between teachers (Fan, 2021).

The introduction of network technologies, cloud services, big data, as well as virtual and augmented reality in teaching practice dramatically increases learning opportunities (Liu et al., 2020). For example, virtual reality (VR) is a technological tool of display that allows users to be placed in a virtual world where situations that would otherwise be difficult to imagine in real life can be created (Hsu, 2021), and augmented reality (AR) provides real-time interaction while combining the virtual and the real worlds (Çetin \& Türkan, 2021). The AR learning environment not only enhances knowledge but also provides students with an opportunity to gain an advanced level of learning experience in distance learning during the pandemic (Eldokhny \& Drwish, 2021). AR introduces important specifics in the professional activities of teachers and in the transformation of the content of education (Soroko, 2021). A higher level of involvement in the educational process can lead to a more holistic understanding of the learning content and also help in the endogenization or internalization of knowledge (Cai et al., 2019). Virtual and augmented technologies (VAR) are at the early stages of implementation as learning platforms in higher education. The rate of implementation of VAR technology in higher education is associated with the teacher's ability to experiment with the educational content of VAR (Marks \& Thomas, 2021). In recent years, there has been a shift towards the 
integration of digital capabilities across specific contexts and/or learning environments while creating a "continuum" of mixed reality (MR) digital experiences based on a combination of different technologies, tools, platforms, and capabilities, as well as providing learning methods not otherwise available along with a more hands-on, immersive and proactive approach to teaching and learning (Allcoat et al., 2021).

This is consistent with the opinion that modern digital technologies make it possible to simulate various professional scenarios and environments that are difficult to demonstrate in physical space. In this regard, educational strategies should be developed taking into account the variety of online services, platforms, and mobile applications that are in the public domain and allow users to make their learning meaningful and practical, as well as to reveal the understanding of the importance of educational activities in the life of a modern person (Yıldırım, 2021).

In our opinion, an effective pedagogical methodology, embedded in the course, is a key to the academic progress of each student. In the current educational practice, STEM learning is gaining popularity and taking root in learning trajectories (Liu et al., 2020). Analyzing the interdisciplinary experience of teaching science and mathematics in higher education focused on research-based learning, 6E learning models, and the use of the innovative learning environment of CreativeLab_Sci \& Math created by the Department of Mathematical and Natural Sciences of the Polytechnic Institute of Santarem (Portugal), researchers concluded that student participation in integrative learning contributes to the formation of a less fragmented view of science and mathematics education. The integration of science and mathematics teaching allows students to develop engagement, critical and creative thinking, reasoning and problem-solving skills while fostering deeper conceptual understanding of both subjects (Mestrinho \& Cavadas, 2018). However, it should be considered that pedagogical transformations depend not only on the intellectual progressiveness of educational institutions but also on the progressiveness of society (Deák et al., 2021).

Although the impact of the pandemic shocked educators at all levels, the emergency also inspired them to search for the solutions to problems they had not faced before (Aldon et al., 2021). A variety of ideas and discussions about the role of educational technologies and changes in the needs of students put forward the importance and priority of innovative solutions in modern pedagogy (Gilbert et al., 2021). Scientists are currently assessing the effectiveness of the global changes in the education system and are trying to find out whether their efforts to create new or adapted learning methods have had a positive impact on students and on the educational process (Jackson, 2021).

\section{Conclusions}

Among the modern trends in educational activities, innovative teaching methods and technologies dominate; they can have a qualitative influence on the effectiveness and efficiency of teaching. An innovative pedagogical methodology with an emphasis on the applied nature of learning in the context of the possibilities of the digital space and with the use of motivational support for the participants in 
the educational process has been described. As part of the pedagogical methodology, online learning is implemented with the help of a learning management system, online communication services, professional mobile applications and AR / VR / XR immersion technologies, Clil technology. The prerogatives of practical educational activities are the update of knowledge and its application in practice; stable development of professional competencies; learning by doing using modern technologies; development of teamwork skills in the process of active social learning; development of creative and critical thinking. In the course of educational activities, the following principles should be implemented: constructivist, problem-oriented, project and research approaches, as well as pedagogical approaches of gamification, simulation, and adaptive learning. In the proposed pedagogical methodology, motivational support is carried out in the field of the formation and promotion of a positive attitude towards fellow students; the development of personal autonomy; the improvement of the skills of self-organization, self-control and management of personal learning activities; the achievement of educational and personal progress; the development of technology literacy in setting educational and professional goals; support for psychological well-being and self-acceptance.

The developed methodology was proven effective in Mathematics Teaching and Molecular Biology classrooms. It qualitatively contributed to the formation of effective and trusting interpersonal relationships in the group and promoted a proactive corporate culture allowing each participant to demonstrate their communication abilities, as well as to develop the skills of mutual assistance and support in group work. The courses allowed students to improve their skills of independent learning, self-organization, responsible decision-making and the ability to critically assess their educational achievements in accordance with personal criteria. The students easily adapted to digital pedagogy, mastered the skills of learning activity management, and effectively used the technological opportunities provided by the courses. The students showed a high level of mastery of the educational material, which was also evidenced by the results of the tests taken after each unit completion. The pedagogical methodology contributed to the formation of a sense of purposefulness and meaningful learning in the students; the educational activities influenced the positive self-esteem of the course participants developing their ability to critically assess their good and bad qualities and to be congruent in group learning interactions.

Acknowledgements Svetlana Kulanina has been supported by the Kazan Federal University Strategic Academic Leadership Program.

Authors' contribution Conceptualization: Umitzhan Kossybayeva, Bagit Shaldykova, Svetlana Kulanina; Methodology: Umitzhan Kossybayeva, Danna Akhmanova; Formal analysis and investigation: Bagit Shaldykova, Danna Akhmanova, Svetlana Kulanina; Writing-original draft preparation: Umitzhan Kossybayeva, Danna Akhmanova; Writing - review and editing: Bagit Shaldykova, Svetlana Kulanina; Funding acquisition: Umitzhan Kossybayeva, Svetlana Kulanina; Resources: Umitzhan Kossybayeva, Bagit Shaldykova; Supervision: Bagit Shaldykova, Danna Akhmanova.

Data, materials and/or Code availability Data, materials and code will be available on request. 


\section{Declarations}

Ethics approval The authors declare that the work is written with due consideration of ethical standards. The study was conducted in accordance with the ethical principles approved by the Ethics Committee of E.A. Buketov Karaganda University and Kazan Federal University.

Consent All participants gave their written informed consent.

Competing interests Authors declare that they have no competing interests.

\section{References}

Abramovich, S., Grinshpan, A. Z., \& Milligan, D. L. (2019). Teaching mathematics through concept motivation and action learning. Education Research International, 2019, 3745406. https://doi.org/ $10.1155 / 2019 / 3745406$

Akugizibwe, E., \& Ahn, J. Y. (2020). Perspectives for effective integration of e-learning tools in university mathematics instruction for developing countries. Education and Information Technologies, 25, 889-903. https://doi.org/10.1007/s10639-019-09995-z

Aldon, G., Cusi, A., Schacht, F., \& Swidan, O. (2021). Teaching mathematics in a context of lockdown: A study focused on teachers' praxeologies. Education Sciences, 11(2), 38. https://doi.org/10.3390/ educsci11020038

Algani, Y. M. A. (2019). Innovative ways to teach mathematics: Are they employed in schools? Journal of Computer and Education Research, 7(14), 496-514. https://doi.org/10.18009/jcer.612199.

Allcoat, D., Hatchard, T., Azmat, F., Stansfield, K., Watson, D., \& von Mühlenen, A. (2021). Education in the digital age: Learning experience in virtual and mixed realities. Journal of Educational Computing Research, 59(5), 795-816. https://doi.org/10.1177/0735633120985120

Bakker, A., Cai, J., \& Zenger, L. (2021). Future themes of mathematics education research: An international survey before and during the pandemic. Educational Studies in Mathematics, 107(1), 1-24. https://doi.org/10.1007/s10649-021-10049-w

Borba, M. C. (2021). The future of mathematics education since COVID-19: Humans-with-media or humans-with-non-living-things. Educational Studies in Mathematics, 108, 385-400. https://doi.org/ 10.1007/s10649-021-10043-2

Cai, S., Liu, E., Yang, Y., \& Liang, J. C. (2019). Tablet-based AR technology: Impacts on students' conceptions and approaches to learning mathematics according to their self-efficacy. British Journal of Educational Technology, 50(1), 248-263. https://doi.org/10.1111/bjet.12718

Çetin, H., \& Türkan, A. (2021). The effect of augmented reality based applications on achievement and attitude towards science course in distance education process. Education and Information Technologies. https://doi.org/10.1007/s10639-021-10625-w

Chen, Z., Cao, H., Deng, Y., Gao, X., Piao, J., Xu, F., Zhang, Y., \& Li, Y. (2021). Learning from home: A mixed-methods analysis of live streaming based remote education experience in Chinese colleges during the COVID-19 pandemic. In Proceedings of the 2021 CHI Conference on human factors in computing systems (pp. 1-16). https://doi.org/10.1145/3411764.3445428.

Childs, E., Mohammad, F., Stevens, L., Burbelo, H., Awoke, A., Rewkowski, N., \& Manocha, D. (2021). An overview of enhancing distance learning through augmented and virtual reality technologies. arXiv preprint arXiv:2101.11000.

Czerkawski, B., \& Berti, M. (2021). Learning experience design for augmented reality. Research in Learning Technology, 29, 2429. https://doi.org/10.25304/rlt.v29.2429.

Deák, C., Kumar, B., Szabó, I., Nagy, G., \& Szentesi, S. (2021). Evolution of new approaches in pedagogy and STEM with inquiry-based learning and post-pandemic scenarios. Education Sciences, 11(7), 319. https://doi.org/10.3390/educsci11070319

Eldokhny, A. A., \& Drwish, A. M. (2021). Effectiveness of augmented reality in online distance learning at the time of the COVID-19 pandemic. International Journal of Emerging Technologies in Learning, 16(9), 198-218. https://doi.org/10.3991/ijet.v16i09.17895 
Fan, L. (2021). Exploring issues about values in mathematics education. ECNU Review of Education, 4(2), 388-395. https://doi.org/10.1177/20965311211016002

Gilbert, A., Tait-McCutcheon, S., \& Knewstubb, B. (2021). Innovative teaching in higher education: Teachers' perceptions of support and constraint. Innovations in Education and Teaching International, 58(2), 123-134. https://doi.org/10.1080/14703297.2020.1715816

Hillmayr, D., Ziernwald, L., Reinhold, F., Hofer, S. I., \& Reiss, K. M. (2020). The potential of digital tools to enhance mathematics and science learning in secondary schools: A context-specific metaanalysis. Computers \& Education, 153, 103897. https://doi.org/10.1016/j.compedu.2020.103897

Hsu, Y. C. (2021). Exploring the effectiveness of two types of virtual reality headsets for teaching high school mathematics. EURASIA Journal of Mathematics, Science and Technology Education, 17(8), em1986. https://doi.org/10.29333/ejmste/10996.

Iji, C. O., \& Abah, J. (2018). Mathematics education for all through information technology innovations. ABACUS: The Journal of the Mathematical Association of Nigeria, 43(1), 89-100.

Jackson, D. C. (2021). Mathematics support - Essential at the best of times, crucial at the worst of times. International Journal of Innovation in Science and Mathematics Education, 29(3), 32-47. https:// doi.org/10.30722/IJISME.29.03.003.

Khirwadkar, A., Khan, S. I., Mgombelo, J., Obradovic-Ratkovic, S., \& Forbes, W. A. (2020). Reimagining mathematics education during the COVID-19 pandemic. Brock Education: A Journal of Educational Research and Practice, 29(2), 42-46.

Khotimah, R. P., Adnan, M., Ahmad, C. N. C., \& Murtiyasa, B. (2021). Science, Mathematics, Engineering, and Mathematics (STEM) education in Indonesia: A literature review. Journal of Physics: Conference Series, 1776, 012028. https://doi.org/10.1088/1742-6596/1776/1/012028

Klingenberg, O. G., Holkesvik, A. H., \& Augestad, L. B. (2020). Digital learning in mathematics for students with severe visual impairment: A systematic review. British Journal of Visual Impairment, 38(1), 38-57. https://doi.org/10.1177/0264619619876975

Leijon, M., Gudmundsson, P., Staaf, P., \& Christersson, C. (2021). Challenge based learning in higher education-A systematic literature review. Innovations in Education and Teaching International. https://doi.org/10.1080/14703297.2021.1892503

Liu, Z. Y., Chubarkova, E., \& Kharakhordina, M. (2020). Online technologies in STEM education. International Journal of Emerging Technologies in Learning, 15(15), 20-32. https://doi.org/10.3991/ijet. v15i15.14677

Luneeva, O. L., \& Zakirova, V. G. (2017). Integration of mathematical and natural-science knowledge in school students' project-based activity. EURASIA Journal of Mathematics Science and Technology Education, 13(7), 2821-2840. https://doi.org/10.12973/eurasia.2017.00720a.

Marks, B., \& Thomas, J. (2021). Adoption of virtual reality technology in higher education: An evaluation of five teaching semesters in a purpose-designed laboratory. Education and Information Technologies. https://doi.org/10.1007/s10639-021-10653-6

Melnikov, Y. B., Gustomesov, V. A., Tsymbalist, O. V., \& Knysh, A. A. (2020). Natural science education: A multiaspect system of models of mathematics. Journal of Physics: Conference Series, 1691, 012024. https://doi.org/10.1088/1742-6596/1691/1/012024

Mestrinho, N., \& Cavadas, B. (2018). Innovation in teacher education: An integrative approach to teaching and learning science and mathematics. In Multidisciplinary digital publishing institute proceedings (Vol. 2, No. 21, p. 1343). https://doi.org/10.3390/proceedings2211343.

Microsoft .(2021). Official web site. Retrieved September 21, 2021, from www.microsoft.com.

Moreno-Guerrero, A. J., Aznar-Díaz, I., Cáceres-Reche, P., \& Alonso-García, S. (2020). E-learning in the teaching of mathematics: An educational experience in adult high school. Mathematics, 8(5), 840. https://doi.org/10.3390/math8050840

Novita, R., \& Herman, T. (2021). Digital technology in learning mathematical literacy, can it helpful? Journal of Physics: Conference Series, 1776, 012027. https://doi.org/10.1088/1742-6596/1776/1/ 012027

O’Dowd, R. (2018). Innovations and challenges in using online communication technologies in CLIL. Theory into Practice, 57(3), 232-240.

Ryff, C. D. (1995). The structure of psychological well-being revisited. Journal of Personality and Social Psychology, 69, 719-727. https://doi.org/10.1037/0022-3514.69.4.719

Santangelo, J., Cadieux, M., \& Zapata, S. (2021). Developing student metacognitive skills using active learning with embedded metacognition instruction. Journal of STEM Education: Innovations and Research, 22(2), 75-87. 
Soroko, N. V. (2021). The augmented reality functions to support the STEM education at general education institutions. Physical and Mathematical Education, 3(29), 24-30. https://doi.org/10.31110/ 2413-1571-2021-029-3-004.

Survio. (2021). Official web site. Retrieved September 21, 2021, from https://www.survio.com/ru/.

Teamer. (2021). Official web site. Retrieved September 21, 2021, from https://coba.tools/teamer.

Wannapiroon, P., Nilsook, P., Kaewrattanapat, N., Wannapiroon, N., \& Supa, W. (2021). Augmented reality interactive learning model, using the imagineering process for the SMART classroom. TEM Journal, 10(3), 1404-1417. https://doi.org/10.18421/TEM103-51.

Yildırım, F. S. (2021). Effectiveness of augmented reality implementation methods in teaching Science to middle school students. International Journal of Curriculum and Instruction, 13(2), 1024-1038.

Publisher's note Springer Nature remains neutral with regard to jurisdictional claims in published maps and institutional affiliations.

\section{Authors and Affiliations}

\section{Umitzhan Kossybayeva ${ }^{1}$ (D) - Bagit Shaldykova ${ }^{2}$. Danna Akhmanova ${ }^{1}$ Svetlana Kulanina ${ }^{3}$}

1 Department of Methods of Teaching Mathematics and Computer Science, E.A. Buketov Karaganda University, Karaganda, Kazakhstan

2 Department of Engineering and Social and Humanitarian Disciplines, Rudny Industrial Institute, Rudny, Kazakhstan

3 Department of Biology and Chemistry, Kazan Federal University, Elabuga, Russian Federation 